\title{
Identification of Mycobacterium tuberculosis in the cerebrospinal fluid of patients with meningitis using nested PCR
}

\author{
NORA RIOS-SARABIA ${ }^{1}$, OLIVIA HERNÁNDEZ-GONZÁLEZ ${ }^{1}$, JORGE GONZÁLEZ-Y-MERCHAND ${ }^{2}$, \\ GUADALUPE GORDILLO ${ }^{1}$, GUILLERMO VÁZQUEZ-ROSALES ${ }^{3}$, LEOPOLDO MUÑOZ-PÉREZ ${ }^{1}$, \\ JAVIER TORRES ${ }^{1}$ and CARMEN MALDONADO-BERNAL ${ }^{4}$
}

\author{
${ }^{1}$ Medical Research Unit on Infectious Diseases, Hospital of Pediatrics, XXI Century National Medical Center, \\ Mexican Social Security Institute, Mexico City 06720; ${ }^{2}$ Laboratory of Molecular Microbiology, Department of Microbiology, \\ National School of Biological Sciences, National Polytechnic Institute, Mexico City 11340; ${ }^{3}$ Department of Infectious Diseases, \\ Hospital of Pediatrics, XXI Century National Medical Center, Mexican Social Security Institute; ${ }^{4}$ Research Laboratory \\ in Immunology and Proteomics, Children's Hospital of Mexico Federico Gomez, Mexico City 06720, Mexico
}

Received August 29, 2015; Accepted July 22, 2016

DOI: $10.3892 / \mathrm{ijmm} .2016 .2698$

\begin{abstract}
Tuberculous meningitis (TBM) is the most severe form of tuberculosis. It is caused by Mycobacterium tuberculosis (M.tuberculosis; MT) and it is very difficult to diagnose. The symptoms are similar to other infectious neurological diseases, such as neurocysticercosis, neuroborreliosis, or herpes viral infection. The aim of this study was to identify tuberculosis (TB) in cases of meningitis with clinical and laboratory evidence suggestive of TBM, and to confirm our findings with molecular tests for TB infection. We recruited patients with neurological symptoms who were examined at the neurology services of Hospitals of Instituto Mexicano del Seguro Social (IMSS) in Mexico City. A total of 144 consecutive patients with suggestive infectious meningitis were initially included; 94 cases of meningitis with clinical and laboratory evidence suggestive of TBM were included, but only 50 of these cases fulfilled the criteria for probable TBM. As the controls, we included 50 cases of meningitis with clinical and laboratory evidence suggestive of non-TBM. Cerebrospinal fluid (CSF) was collected from all 100 patients (cases and controls) and tested for TB by multiplex and nested PCR analyses. Nested PCR detected $0.1 \mathrm{fg}$ of M.tuberculosis DNA. TB infection was confirmed with molecular tests in 49 patients from the 50 cases suggestive of TBM and in 1 of the 50 non-TBM cases. The analysis exhibited a sensitivity of $98.0 \%$, a specificity of $92.0 \%$, a positive predictive value of $88.0 \%$ and a negative predictive value of $98.0 \%$. The use $\mathrm{CSF}$ for the analyses proved to be effective for the rapid diagnosis
\end{abstract}

Correspondence to: Dr Carmen Maldonado-Bernal, Research Laboratory in Immunology and Proteomics, Children's Hospital of Mexico Federico Gomez, Dr. Márquez 162, Colonia Doctores, Delegación Cuauhtémoc, Mexico City 06720, Mexico

E-mail: cmaldobe@yahoo.com

Key words: tuberculous meningitis, Mycobacterium tuberculosis, multiplex PCR, nested PCR, cerebrospinal fluid of TBM using a developed system of multiplex and nested PCR analyses in patients presenting neurological symptoms.

\section{Introduction}

Tuberculosis (TB) remains among the leading infectious causes of death in developing nations, with Mycobacterium tuberculosis (M.tuberculosis; MT) as the species responsible for most of these deaths $(1,2)$. According to the World Health Organization (WHO), in 2014, the estimated number of tuberculosis cases was 9 million, including 3.5 million new cases and 1.1 million human immunodeficiency virus (HIV)-positive cases. WHO reported a prevalence of 370 tuberculosis cases per 100,000 individuals in the United States (3). In Mexico and other developing nations, tuberculosis is ranked 17th among the leading causes of all deaths in the working-aged general population (4).

The two main presentations of tuberculosis are pulmonary and extra pulmonary (5). Extra-pulmonary tuberculosis results from bacterial spread to other sites in the body, and occurs in approximately $10 \%$ of patients hospitalized with pulmonary tuberculosis (6). Tuberculous meningitis (TBM) is the most severe form of the infection, which is usually caused by M.tuberculosis and poses a serious threat to human health worldwide (7). If left untreated, the mortality associated with TBM is almost $100 \%$ and delayed treatment may lead to permanent neurological damage $(3,8)$. The conventional 'gold standard' bacteriological methods, namely direct smear and culture isolation, are hardly able to detect $M$. tuberculosis in the cerebrospinal fluid (CSF) of patients with TBM. The clinical severity of TBM demands a rapid diagnosis and appropriate treatment in order to improve the clinical outcome. In infections of the central nervous system, such as TBM, the bacterial load is extremely low, thus making diagnoses based on the culture or staining of CSF difficult, as the results are usually negative. Furthermore, the clinical manifestations of TBM are often non-specific, similar to those of other forms of meningitis, such as neurocysticercosis, neuroborreliosis, or viral infections; thus, its diagnosis is currently based on 
clinical characteristics, radiological tests, responses to treatment and in the characteristics of CFS (9-14).

Molecular tests, in particular those based on the PCR for amplification of genes specific for the infecting organism may identify a wide variety of microorganisms, including mycobacteria (15-18). The analysis of the genomic sequence of M.tuberculosis (19) and studies on comparative genomics $(20,21)$ have identified major deletions that specifically characterize different species of the M.tuberculosis complex, and are useful in differentiating these from non-tuberculous mycobacteria (22-25). Some studies have reported the use of PCR and quantitative PCR to identify M.tuberculosis in the CSF of patients with TBM, with varying sensitivity and specificity $(25,26)$. However, the reported methods are based primarily on primers that bind IS6110, which allow the identification of the genus of the tuberculosis complex, but does not discern between species. Thus, the aim of this study was to identify TB in cases of meningitis with clinical and laboratory evidence suggestive of TBM, and to confirm our findings with molecular tests for TB infection.

\section{Patients and methods}

Bacterial strains and DNA isolation. The mycobacterial strains used as controls were M.tuberculosis H37Rv (donated by The Pasteur Institute, Paris, France), M. bovis AN5 (35734; ATCC, Rockville MD, USA), M. avium, M. intracellulare and $M$. habana (clinical isolates previously identified by rRNA 16S sequencing), M. celatum (51130; ATCC) and M. marinum (clinical isolate given by Dr Ruth Parra of the National Medical Center, Mexico City, Mexico). The strains were grown in Middlebrook $7 \mathrm{H} 9$ broth (Difco, Franklin Lakes, NJ, USA) and DNA was isolated using the phenol-chloroform method, as previously described $(27,28)$. DNA was precipitated with isopropanol and resuspended in $50 \mu \mathrm{l}$ of distilled water, and a $10 \mu \mathrm{l}$ aliquot was used for PCR amplification (100 ng of DNA for the test), as previously described (15).

Ethics statement. The study protocol was approved by the Ethics Committee of the Mexican Social Security Institute (IMSS).

Patient selection. We recruited 144 consecutive patients with suspected meningitis and neurological symptoms who were examined at the neurology services of 4 Hospitals of IMSS in Mexico City between June 2008 and February 2013. The patients were both male and female, and included children and adults. Written informed consent was obtained from all the patients or the parents/legal guardians prior to recruitment. A total of 94 cases of meningitis with clinical and laboratory evidence suggestive of TBM were included, but only 50 of these cases fulfilled the criteria for probable TBM, the other 44 cases were eliminated. As the controls, we included 50 cases with neurological disease other than TBM, such as neuropathy, neurocysticercosis, neuroborreliosis, or viral infections. CSF was extracted from these patients as part of the protocol for diagnosis; a fraction of the sample was processed immediately for DNA isolation and was stored at $-70^{\circ} \mathrm{C}$ until analysis.

Definition of case and control. As the bacterial load in the CSF is extremely low and culture is difficult using these samples, we diagnosed the cases of TBM based on clinical findings, CSF
Table I. Baseline characteristics of tuberculous meningitis (TBM) cases.

\begin{tabular}{lc} 
Characteristics & TBM cases, $\mathrm{n}$ \\
\hline Age (years) & \\
$<18$ & $21(42)$ \\
$>18$ & $29(58)$ \\
Gender & \\
Male & $27(54)$ \\
Female & $23(46)$ \\
Clinical manifestation & \\
Headache & \\
Fever & $32(64)$ \\
Neck stittness & $19(32)$ \\
Vomitting & $18(36)$ \\
Abnormal behaivior & $18(36)$ \\
Unconsciousness & $26(52)$ \\
Drowsiness & $3(6)$ \\
Seizures & $11(22)$ \\
Nausea & $24(48)$ \\
Blurred vision & $10(20)$ \\
\end{tabular}

TBM (cases), $\mathrm{n}=50$; average age, $<18[10.8(0.5-18)]$ and $>18[42.3$ (19-63) years].

Table II. The cerebrospinal fluid (CSF) characteristics of the tuberculous meningitis (TBM) cases and non-TMB controls.

\begin{tabular}{lcc}
\hline CSF characteristics & $\begin{array}{c}\text { TBM } \\
\text { cases }\end{array}$ & $\begin{array}{c}\text { Non-TBM } \\
\text { controls }\end{array}$ \\
\hline Total cell count $\left(\right.$ cell $\left./ \mathrm{mm}^{3}\right)$ & $96.5(17-176)$ & $59(12-106)$ \\
Sugar $(\mathrm{mg} / \mathrm{dl})$ & $49(15-83)$ & $65(9-121)$ \\
Protein $(\mathrm{mg} / \mathrm{dl})$ & $151(98-204)$ & $74(53-95)$ \\
\hline
\end{tabular}

criteria or both. The clinical criteria of meningitis included headache, fever and neck stiffness, with or without an altered consciousness. The CSF criteria were a cell count $>10$ cells/ $\mathrm{mm}^{3}$, a protein concentration $>45 \mathrm{mg} / \mathrm{dl}$ and a glucose concentration $<40 \mathrm{mg} / \mathrm{dl}$ (9), either alone or in combination. TBM was defined as meningitis with typical CSF findings in conjunction with either suggestive chest X-ray abnormalities or suggestive TB lymphadenitis. We chose to use clinical and laboratory data to define the cases and the controls, as previously described $(9,13,14)$. A TBM case was defined as a patient suffering from fever, headaches and meningismus (stiff neck), along with focal neurological deficits, behavioural changes and alterations in consciousness, with CSF characteristics of moderate lymphocytic pleocytosis, moderately elevated protein levels and hypoglycorrachia (Tables I and II) (12). In addition, all the TBM cases should respond clinically and radiologically to specific anti-tuberculosis treatment. A history of a positive tuberculin skin test, or exposure to tuberculosis, was also considered as risk for TBM. A non-TBM case was defined as a patient with a confirmed diagnosis of neuropathy other 
Table III. Primers used in the study.

\begin{tabular}{|c|c|c|c|c|}
\hline $\begin{array}{l}\text { Gene } \\
\text { fragment }\end{array}$ & $\begin{array}{l}\text { Primer target } \\
\text { (description) }\end{array}$ & $\begin{array}{l}\text { Primer sequences } 5^{\prime} \rightarrow 3^{\prime} \\
\quad(\text { foward/reverse) }\end{array}$ & $\begin{array}{l}\text { Amplicon } \\
\text { size (bp) }\end{array}$ & Authors/year/(Refs.) \\
\hline p32 & $\begin{array}{l}\text { MT1 } \\
\text { MT2 }\end{array}$ & $\begin{array}{l}\text { TTC CTG ACC AGC GAG CTG CCG } \\
\text { CCC CAG TAC TCC CAG CTG TGC }\end{array}$ & 506 & $\begin{array}{l}\text { Del Portillo et al, 1991, } 1996(30,31) \\
\text { Nava et al, } 2005(33)\end{array}$ \\
\hline IS6110 & $\begin{array}{l}\text { IS } 5 \\
\text { IS } 6\end{array}$ & $\begin{array}{l}\text { CGG AGA CGG TGC GTA AGT GG } \\
\text { GAT GGA CCG CCA GGG CTT GC }\end{array}$ & 984 & $\begin{array}{l}\text { Del Portillo et al, 1991, } 1996(30,31) \\
\text { Nava et al, } 2005 \text { (33) }\end{array}$ \\
\hline$m t p 40$ & $\begin{array}{l}\text { PT1 } \\
\text { PT2 }\end{array}$ & $\begin{array}{l}\text { CGG CAA CGC GCC GTC GGT GG } \\
\text { CCC CCC ACG GCA CCG CCG GG }\end{array}$ & 396 & $\begin{array}{l}\text { Del Portillo et al, } 1991(30,31) \\
\text { Herrera and Segovia, } 1996(32)\end{array}$ \\
\hline $\begin{array}{l}\text { Internal } \\
\text { fragment } \\
\text { of } m t p 40\end{array}$ & $\begin{array}{l}\text { PT3 } \\
\text { PT4 }\end{array}$ & $\begin{array}{l}\text { CAC CAC GTT AGG GAT GCA CTG C } \\
\text { CTG ATG GTC TCC GAC ACG TTC G }\end{array}$ & 223 & Gori et al, 1996 (35) \\
\hline
\end{tabular}

than TBM. From our examination, there were 50 patients who fullfiled the criteria for TBM (the cases) and 50 patients who fulfilled the criteria for the controls (non-TBM).

Sample size calculation. The sample size was estimated with the EPI info 3.5.1 (2008) programme, aiming to achieve 90\% sensitivity for our multiplex-nested PCR analysis of the CSF of patients with neurological manifestations suggestive of TBM $(26,29)$. The sample size calculation was 20 cases and 20 controls. We recruited 50 cases and 50 controls for this study.

Multiplex and nested PCR. We used $100 \mathrm{ng}$ of DNA from the $M$. tuberculosis strain H37Rv to standardize the test. The sequences of the primers are shown in Table III. In the initial amplification, primers MT1 and MT2 amplified the gene encoding the $32-\mathrm{kDa} \alpha$ antigen present in all described mycobacteria, whereas primers IS5 and IS6 amplified the IS6110 insertion element $(30,31)$, and PT1 and PT2 were used to amplify the species-specific gene $m t p 40$. Nested PCR further amplified an internal region of the mtp 40 gene of M.tuberculosis (32). All reactions were performed in a final volume of $25 \mu \mathrm{l}$, with $10 \mathrm{X}$ reaction buffer, $1.25 \mathrm{U}$ of Taq DNA polymerase, $0.2 \mathrm{mM}$ of each deoxynucleotide, $2.5 \mathrm{mM} \mathrm{MgCl}_{2}, 10 \mathrm{pmol}$ of MT1 and MT2, 15 pmol of IS5 and IS6, and $20 \mathrm{pmol}$ of PTI and PT2. The cycling parameters for the initial PCR were $94^{\circ} \mathrm{C}$ for $5 \mathrm{~min}$, followed by 30 cycles of denaturation at $94^{\circ} \mathrm{C}$ for $1 \mathrm{~min}$, annealing at $71^{\circ} \mathrm{C}$ for $2 \mathrm{~min}$ and extension at $72^{\circ} \mathrm{C}$ for $3 \mathrm{~min}$, followed by a final extension at $72^{\circ} \mathrm{C}$ for $10 \mathrm{~min}$. Following amplification, the PCR products were analysed by horizontal electrophoresis on 2.0\% agarose gels (33) using DNA molecular marker $1 \mathrm{~kb}$ (Invitrogen Life Technologies, Carlsbad, CA, USA). The multiplex PCR products were subjected to nested PCR under the following conditions: $94^{\circ} \mathrm{C}$ for $5 \mathrm{~min}$, followed by 30 cycles of $94^{\circ} \mathrm{C}$ for $1 \mathrm{~min}, 74^{\circ} \mathrm{C}$ for $2 \mathrm{~min}$, and $72^{\circ} \mathrm{C}$ for $2 \mathrm{~min}$, followed by a final extension at $72^{\circ} \mathrm{C}$ for $7 \mathrm{~min}$.

Laboratory sensitivity and specificity. Before testing the clinical samples, the specificity of the assay was tested using DNA from the following Mycobacterium species: $M$. tuberculosis H37Rv, M. bovis AN5, M. intracellulare, M. avium, M. celatum, M. habana and M. marinum, and DNA from Stap hylococcus aureus (S. aureus) and Escherichia coli (E. coli) (clinical isolate from the clinical laboratory of Pediatric
Hospital of the National Medical Center, Mexico City, Mexico). The sensitivity of the assay was estimated using 10-fold dilutions of M.tuberculosis DNA, ranging from $100 \mathrm{ng}$ to $0.01 \mathrm{fg}$.

Processing of the clinical samples. All CSF samples from the patients with meningeal infection were analyzed by multiplex and nested PCR, and the study was blinded. An aliquot of $500 \mu \mathrm{l}$ of each CSF was subjected to thermal shock, and centrifuged at $17,000 \mathrm{x}$ g for $15 \mathrm{~min}$. The DNA was isolated from the pellet with guanidine isothiocyanate according to the procedure previously described by Chomczynski and Sacchi (27) and Chomczynski (28), and stored at $-70^{\circ} \mathrm{C}$ until use. A $100 \mathrm{ng}$ sample of DNA from each CSF sample was used for the multiplex and nested PCR. The results of PCR for the cases and controls were used to estimate the clinical specificity and sensitivity of the test.

DNA sequences and analysis. Four of the amplified nested PCR products from the clinical samples were purified using the QIAEX II Gel Extraction kit (Qiagen, Hilden, Germany), and sequenced with the CEQ 8800 Genetic Analysis system (Beckman Coulter, Inc., Brea, CA, USA), according to the manufacturer's instructions. The sequences generated were analyzed with the BLAST tool (available online at www.ncbi. nih.gov/BLAST) and aligned with the available $M$. tuberculosis $\mathrm{H} 37 \mathrm{Rv}$ genome sequence database, accessible at http://genolist. pasteur.fr/Tuberculist, to estimate the degree of homology.

Statistical analysis. Measures of central tendency were the descriptive statistics used to analyze the quantitative variables. A $2 \times 2$ contingency table was used to determine the sensitivity (S), specificity (E), positive predictive value (PPV) and negative predictive value (NPV) of the diagnostic test using clinical samples (27).

\section{Results}

Multiplex and nested PCR. The sizes of the amplified fragments were sufficiently different to be distinguishable on agarose gels; the primers had no potential matches with sequences at non-specific target sites, and the optimal DNA-primer annealing temperatures were almost the same for all template-primer combinations (15). Fig. 1A shows the fragments amplified when each individual primer set was used 


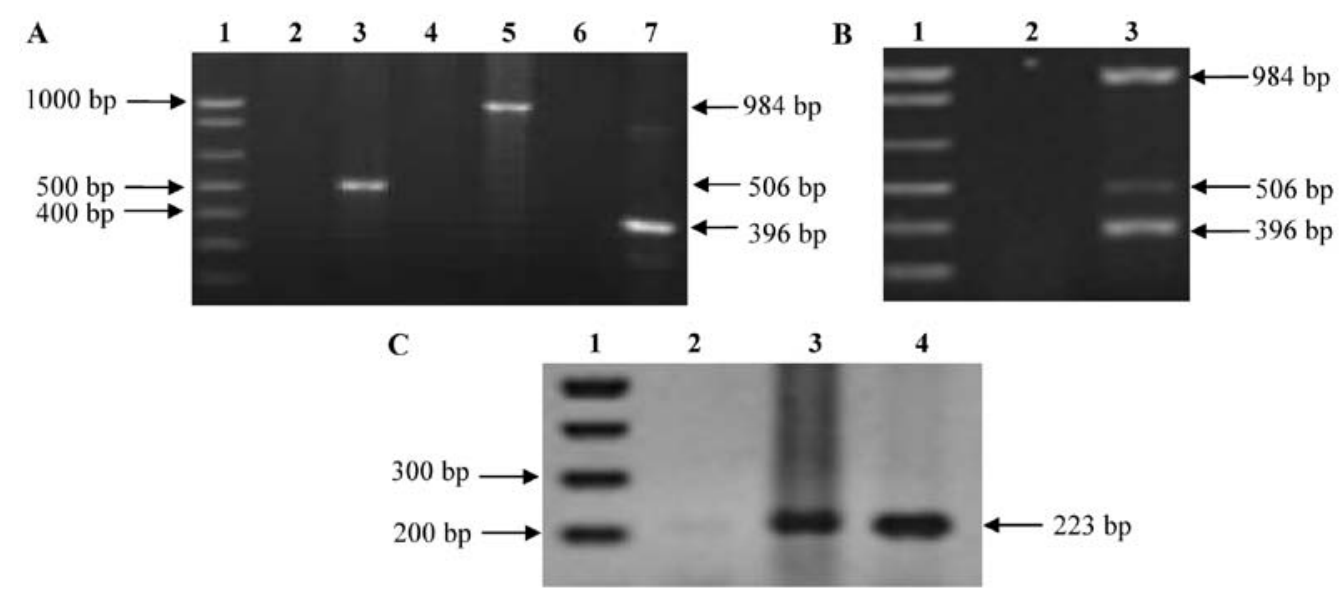

Figure 1. Electrophoresis of PCR and nested PCR products of Mycobacterium tuberculosis (M. tuberculosis) H37Rv DNA. (A) Amplification of $p 32$, IS6110 and $m t p 40$ fragments by conventional PCR. Lane 1, DNA molecular marker $1 \mathrm{~kb}$; lane 2, negative control of MT1 and MT2 primers; lane 3, p32 amplification fragment; lane 4, negative control of IS5 and IS6 primers; lane 5, IS6110 amplification fragment; lane 6, negative control of PT1 and PT2 primers; and lane 7, $m t p 40$ amplification fragment. (B) Amplification of $p 32$, IS6110 and $m t p 40$ fragments by multiplex PCR lane 1, DNA molecular marker $1 \mathrm{~kb}$; lane 2, negative control; and lane 3, amplification products of multiplex PCR of M. tuberculosis H37Rv DNA. (C) Amplification of internal fragment of $m t p 40$ by nested PCR. Lane 1, DNA molecular marker $1 \mathrm{~kb}$; lane 2, negative control; lanes 3 and 4, M. tuberculosis H37Rv DNA.

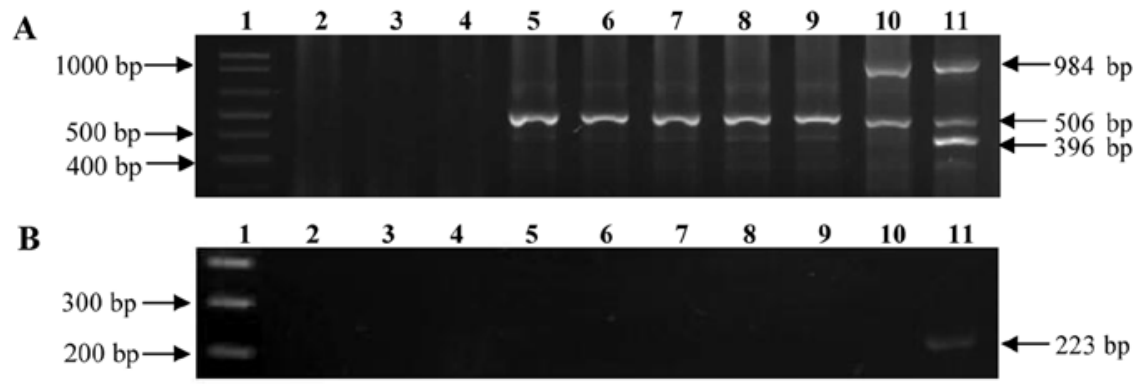

Figure 2. Amplification of DNA from other bacteria. (A) Multiplex PCR products. (B) Nested PCR products. Lane 1, DNA molecular marker $1 \mathrm{~kb}$; lane 2 , negative control; lane 3, Escherichia coli (E. coli) DNA; lane 4, Staphylococcus aureus (S. aureus) DNA; lane 5, M. habana DNA; lane 6, M. celatum DNA, lane 7, M. marinum DNA; lane 8, M. avium DNA; lane 9, M. intracellulare DNA; lane 10, M. bovis AN5 DNA; and lane 11, Mycobacterium tuberculosis (M. tuberculosis) H37Rv DNA.

separately. Fig. 1B, lane 3, shows the simultaneous amplification of the 3 fragments. A nested PCR was used to increase the sensitivity of the system, with a pair of primers that amplifies a fragment of $223 \mathrm{bp}$, corresponding to the internal region of the species-specific sequence of the mtp 40 gene (Fig. 1C).

Laboratory specificity and sensitivity of the multiplex and nested PCR system. The specificity of the assay was evaluated with DNA from different Mycobacterium strains (M. tuberculosis, M. bovis AN5, M. intracellulare, M. avium, M. celatum, $M$. habana and M. marinum) and DNA from S. aureus and E. coli. Following multiplex PCR amplification, M. tuberculosis DNA amplify the 3 expected bands of genus (506 bp), complex (984 bp) and species (396 bp), and M. bovis DNA amplify the 2 expected bands of 506 and $984 \mathrm{bp}$. We also tested DNA from other Mycobacterium species (M. intracellulare, M. avium, M. celatum, M. habana and M. marinum), and in all these strains, only the fragment corresponding to the $p 32$ gene of the Mycobacterium genus was amplified. Finally, no amplification was observed with any of the primers when DNA form $S$. aureus and E. coli was tested (Fig. 2A).

These results confirm that multiplex PCR is specific for M. tuberculosis. Moreover, the products obtained from the multiplex PCR were reamplified in the nested PCR, and the internal fragment of the $m t p 40$ gene only amplified with the M. tuberculosis DNA, confirming that this system specifically identifies M.tuberculosis (Fig. 2B).

The sensitivity of the multiplex PCR assay was $10 \mathrm{ng}$ of M. tuberculosis H37Rv DNA where it amplified the 3 expected products (Fig. 3A). However, the sensitivity of the nested PCR was $0.1 \mathrm{fg}$ of DNA for the fragment corresponding to an internal region of the $m t p 40$ gene (Fig. 3B).

CSF sample analysis. Following the standardization of the multiplex and nested PCR system with the Mycobacterium strain, we assessed its usefulness in the CFS samples obtained from clinical cases suggestive of TBM. We analyzed $100 \mathrm{CSF}$ samples from patients with diverse neurological symptoms, from 50 patients with a clinical diagnosis of TBM (cases) and 50 patients with a confirmed neurological aetiology other than TBM (controls). In the initial multiplex PCR, only one (patient 3) of the $100 \mathrm{CSF}$ samples amplified a fragment of $396 \mathrm{bp}$ corresponding to the mtp40 gene (Fig. 4A). In the nested PCR, the 223-bp amplification product of the mtp40 gene specific for M. tuberculosis was amplified from 53 samples (Fig. 4B). Forty-nine of these samples corre- 


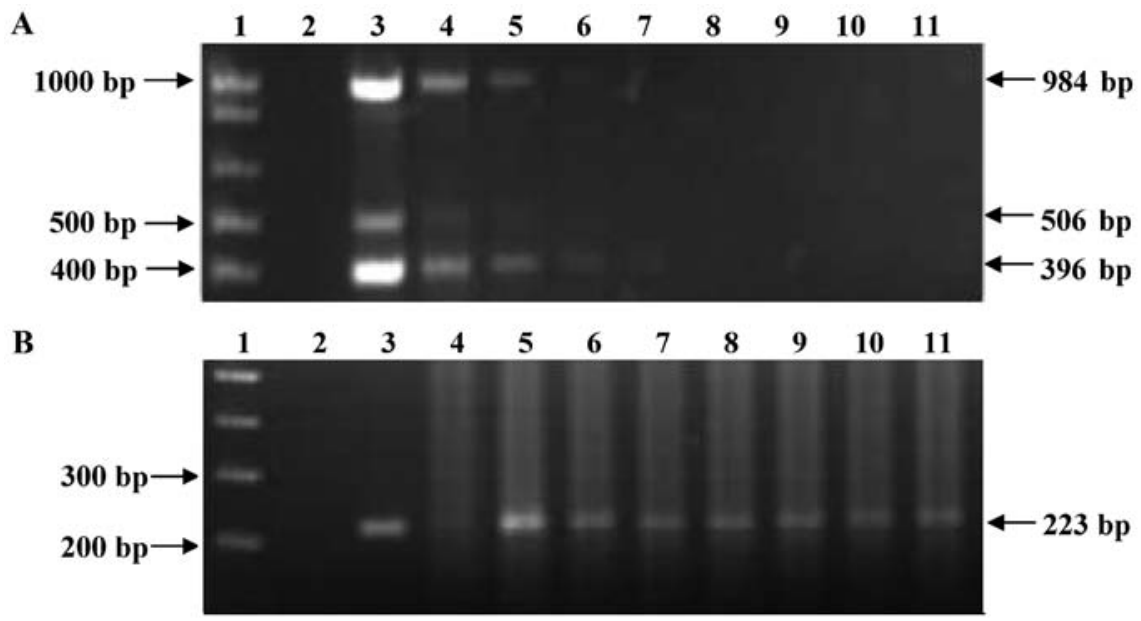

Figure 3. Sensitivity test of the multiplex and nested PCR for detect Mycobacterium tuberculosis (M. tuberculosis) DNA. (A) Multiplex PCR products of different concentrations of $M$. tuberculosis H37Rv DNA. (B) Nested PCR products from multiplex PCR of different concentrations of $M$. tuberculosis H37Rv DNA. Lane 1, DNA molecular marker $1 \mathrm{~kb}$; lane 2, negative control; lane 3, $100 \mathrm{ng}$; lane 4, $10 \mathrm{ng}$; lane 5, $1 \mathrm{ng}$; lane 6, $100 \mathrm{pg}$; lane 7, $10 \mathrm{pg}$; lane 8, $1 \mathrm{pg}$; lane 9 , $100 \mathrm{fg}$; lane 10, $10 \mathrm{fg}$; and lane 11, $1 \mathrm{fg}$.

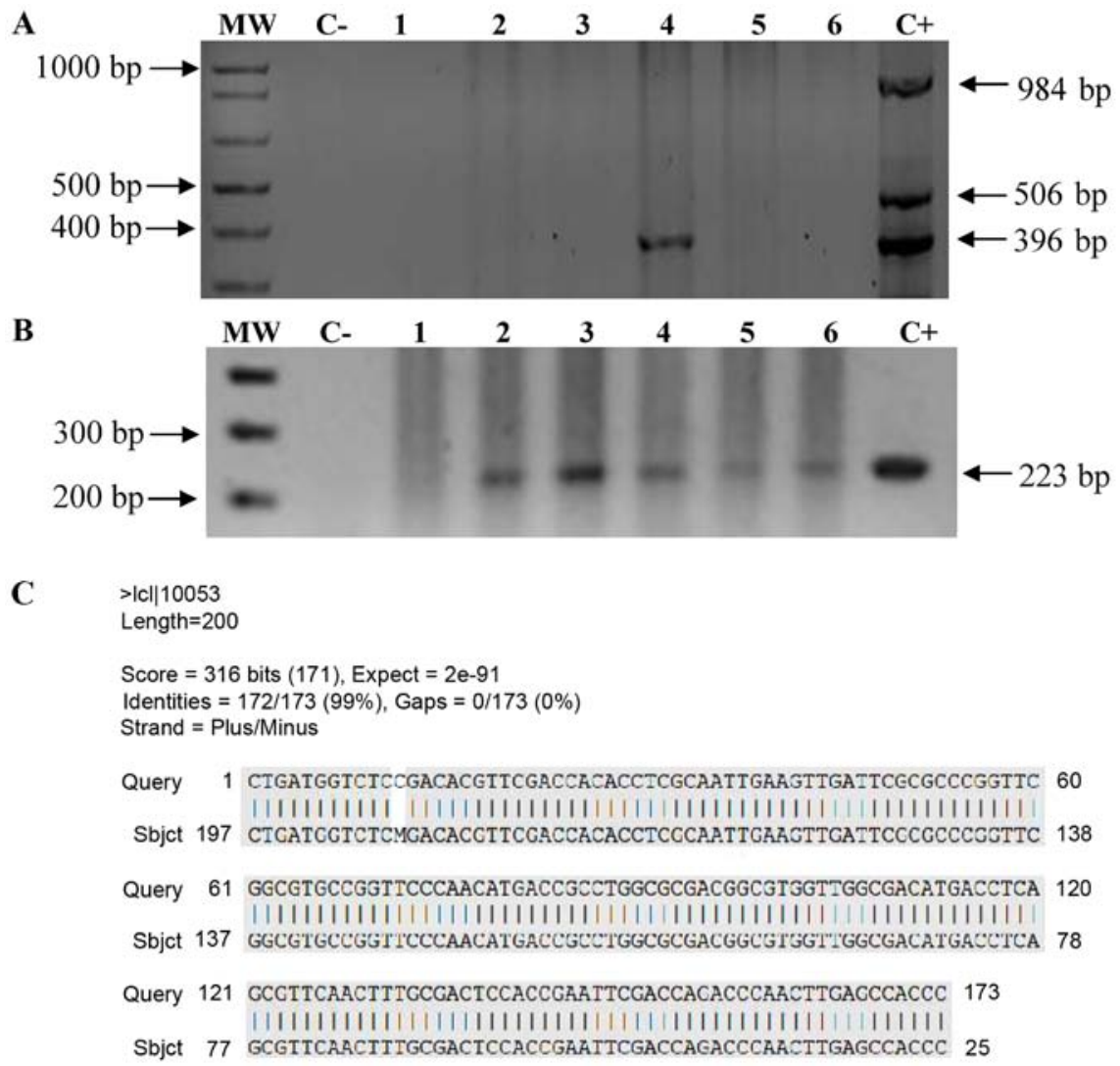

Figure 4. Multiplex and nested PCR for detect Mycobacterium tuberculosis (M. tuberculosis) in cerebrospinal fluid (CSF). (A) Multiple-PCR test applied to CSF samples from patients with neurologic diseases. (B) Nested PCR products from multiple-PCR products. Lane 1, patient 16 (true negative); lane 2, patient 11; lane 3, patient 8; lane 4, patient 3; lane 5, patient 12; and lane 6, patient 17 (patient 11,8,3,12 and 17 were true positive). MM, molecular marker $1 \mathrm{~kb}$; C-, negative control; C+, positive control DNA from M. tuberculosis H37Rv strain. (C) Alignment of the mtp40 internal fragment with sequence of nested PCR product using PT3 and PT4 primers. The highlighted positions indicate the sequence of the $m t p 40$ internal fragment (Query) from 2630676 to 2630827 positions, and sequence of nested PCR product (Sbjct).

sponded to the group of cases and responded to specific treatment against $M$. tuberculosis, thus confirming the presence of M. tuberculosis DNA in the CSF. Moreover, we had one false-negative sample in the nested PCR. The negative control run with each set of test samples produced no visible product on ethidium bromide-stained agarose gel.
DNA sequence of $P C R$ products. We determined the DNA sequence of the amplified 223-bp fragment corresponding to the mtp 40 gene from 4 positive samples to confirm that the product was specific for $M$. tuberculosis. The sequence alignment showed $99 \%$ homology between the nested PCR products and the corresponding region of the $m t p 40$ gene (Fig. $4 \mathrm{C}$ ). 
Table IV. Sensitivity and specificity as a diagnostic test for tuberculous meningitis (TBM).

\begin{tabular}{lc}
\hline Nested PCR & $\%$ \\
\hline Sensitivity & 98 \\
Specificity & 92 \\
PPV & 88 \\
NPV & 98
\end{tabular}

PPV, positive predictive value; NPV, negative predictive value.

Sensitivity and specificity of the test. The clinical sensitivity of this method was $98.0 \%$ and its specificity was $88.0 \%$; the positive predictive value (PPV) was $91.0 \%$ and the negative predictive value (NPV) was $98.0 \%$ (Table IV).

\section{Discussion}

The suboptimal and often delayed results of traditional microbiological techniques used in the diagnosis of TBM underscore the need for a more rapid and more accurate diagnostic method to facilitate early treatment. Several molecular-based methods used for the diagnosis of tuberculosis in respiratory specimens have been evaluated for their applicability to the diagnosis of TBM (23). Many of these methods have failed with CSF samples, mainly due to the fact that the number of bacilli typically present in TBM is low and that amplification inhibitors are present in the CSF. Commercially available methods of nucleic acid amplification (NAA) for the direct detection of the M. tuberculosis complex have been approved in the United States for testing respiratory specimens; Ling et al, performed an extensive literature search and identified a total of 125 separate studies from 105 articles that reported NAAT results from respiratory specimens. The results showed that sensitivity and specificity estimates for commercial NAATs in respiratory specimens were highly variable, with sensitivity lower and more inconsistent than specificity. Thus, summary measures of diagnostic accuracy are not clinically meaningful. The use of different cut-off values and the use of specimens other than sputum could explain some of the observed heterogeneity (34). However, there are few NAA methods that have been approved for testing the CSF and several studies have evaluated their performance in patients with $\operatorname{TBM}(31,32)$.

The PCR system also has been used as an epidemiological tool in strain classification $(23,24)$. The most widely used target sequence for the diagnosis of tuberculosis has been the IS6110 insertion element, present in a different number of copies in the genome of species of the M. tuberculosis complex $(12,35)$ and PCR techniques based on this sequence have shown to be useful for diagnosis. However, studies have demonstrated that some M. tuberculosis strains do not carry the IS6110 sequence $(36,37)$. Therefore, the use of a PCR method based on the detection of IS6110 for the diagnosis of M. tuberculosis may in some cases lead to false-negative results. Additionally, PCR-based diagnoses based exclusively on the IS6110 sequence would also fail to distinguish $M$. tuberculosis from other mycobacteria of the M.tuberculosis complex.
In the present study, we used the multiplex PCR method described by Del Portillo et al $(30,31)$ to detect M. tuberculosis in pulmonary-type tuberculosis, with some modifications to identify M. tuberculosis in CSF samples. Additionally, we used the nested PCR described by Herrera and Segovia (32). In this study, we demonstrated that using a multiplex and nested PCR system, it is possible to simultaneously amplify the $\alpha$ antigen gene (p32), which identifies the Mycobacterium genus, the IS6110 insertion element and the species-specific $m t p 40$ gene. The nested amplification of a 396-bp fragment corresponding to the $m t p 40$ gene ensures that the results are specific for M.tuberculosis. In addition, the nested PCR allowed us to reach a limit of detection to $0.1 \mathrm{fg}$ of mycobacterial DNA, which theoretically would allow the detection of one bacterium in the sample (16). The PCR amplification of the $m t p 40$ sequence provides a sensitivity and specific method for the diagnosis of tuberculosis $(35,38)$ and it may be useful for the identification of M. tuberculosis, as $98.5 \%$ of strains possess this gene (39). We used a multiplex-PCR method followed by a nested PCR, reaching high specificity and sensitivity.

With the multiplex PCR we were able to detect only the $m t p 40$ gene in a single CSF sample; this may be due to the extremely low number of bacteria in the CSF. However, with the nested PCR, we detected the presence of M. tuberculosis in 53 patients with the amplification of the species-specific $m t p 40$ gene. The products of the nested PCR were sequenced to further confirm that the amplified fragment corresponded to the $m t p 40$ M. tuberculosis gene, and demonstrated that the sequence had a $99 \%$ homology with the $m t p 40$ gene. Thus, we were able to detect the presence of M. tuberculosis in the CSF samples of patients with suggested TBM using a species-specific multiplex and nested PCR test.

Our test showed a sensitivity of $98.0 \%$ and a specificity of $88.0 \%$ for the diagnosis of TBM in CSF samples, which are better than those reported previously $(40,41)$. In relation to the false-negative result, it is possible that a fraction of $m t p 40$ gene was excised by IS6110 recombination as previously described Vera-Cabrera et al (42), which could explain the lack of genes in some M. tuberculosis strains described by Weil et al (43). Concerning the false-positive results, we suggest that they may represent cases of co-infection, where clinical diagnosis could have masked the M. tuberculosis symptoms, focusing on the diagnosis of the other disease. The test presented a reasonably good PPV (91.0\%) and NPV (98.0\%), which contrast with the findings reported by Lima et al (37), who applied a nested PCR to the peripheral blood samples from patients with extra pulmonary tuberculosis, with a rather low PPV (55.6\%) and an acceptable NPV (92.7\%).

In conclusion, the present study demonstrates that the identification of M. tuberculosis in the CSF of patients with meningitis is possible using a developed system of multiplex and nested PCR. This study supports the implementation of two molecular tests as a sensitive and specific diagnostic tool, which offers an improved alternative for the diagnosis of TBM. The multiplex-nested PCR test is a rapid, sensitive and specific tool which may have a beneficial impact on the management of patients with suspected TBM, allowing a more timely anti-tuberculosis treatment to reduce sequelae and mortality. 


\section{Acknowledgements}

The present study was supported by the Instituto de Ciencia y Tecnología del Distrito Federal (ICyTDF), grant no. ICyTDF/DSBMA/350/2009 and the Instituto Mexicano del Seguro Social (IMSS), grant no. FIS/IMSS/PROT/G09/757.

\section{References}

1. Mazars E, Lesjean S, Banuls AL, Gilbert M, Vincent V, Gicquel B, Tibayrenc M, Locht C and Supply P: High-resolution minisatellite-based typing as a portable approach to global analysis of Mycobacterium tuberculosis molecular epidemiology. Proc Natl Acad Sci USA 98: 1901-1906, 2001.

2. Puccioni-Sohler M and Brandão CO: Factors associated to the positive cerebrospinal fluid culture in the tuberculous meningitis. Arq Neuropsiquiatr 65: 48-53, 2007.

3. World Health Organization: Global tuberculosis report 2015 http://www.who.int/tb/publications/global_report/en/. Accessed August, 2015.

4. Ministry of Health in Mexico: National system of epidemiological surveillance. Single system of information (Sistema Nacional de Vigilancia Epidemiológica. Sistema Único de Información. Secretaría de Salud, México). Epidemiologia 29: 5-6, 2006.

5. Procedures manual of standards for epidemiological surveillance of mycobacteriosis (tuberculosis and leprosy). Available: http:// www.epidemiologia.salud.gob.mx/doctos/infoepid/vig_epid_ma nuales/17_2012_Manual_Micobacteriosis_vFinal_9nov12.pdf (In Spanish).

6. Abter EIM, Schaening O, Barbour RL and Lutwick LI: Tuberculosis in the adult. In: Tuberculosis: A Clinical Handbook. Lutwicick LI (ed). Chapman and Hall Medical, London, pp54-101, 1995.

7. Golden MP and Vikram HR: Extrapulmonary tuberculosis: an overview. Am Fam Physician 72: 1761-1768, 2005.

8. Donald PR and Schoeman JF: Tuberculous meningitis. N Engl J Med 351: 1719-1720, 2004

9. Ahuja GK, Mohan KK, Prasad K and Behari M: Diagnostic criteria for tuberculous meningitis and their validation. Tuber Lung Dis 75: 149-152, 1994.

10. González-Martín J, García-García JM, Anibarro L, Vidal R, Esteban J, Blanquer R, Moreno S and Ruiz-Manzano J: Consensus document on the diagnosis, treatment and prevention of tuberculosis. Arch Bronconeumol 46: 255-274, 2010 (In Spanish).

11. Haldar S, Sharma N, Gupta VK and Tyagi JS: Efficient diagnosis of tuberculous meningitis by detection of Mycobacterium tuber culosis DNA in cerebrospinal fluid filtrates using PCR. J Med Microbiol 58: 616-624, 2009

12. Rock RB, Olin M, Baker CA, Molitor TW and Peterson PK Central nervous system tuberculosis: Pathogenesis and clinical aspects. Clin Microbiol Rev 21: 243-261, 2008.

13. Thwaites GE and Tran TH: Tuberculous meningitis: many questions, too few answers. Lancet Neurol 4: 160-170, 2005.

14. Venkataswamy MM, Rafi W, Nagarathna S, Ravi V and Chandramuki A: Comparative evaluation of BACTEC 460TB system and Lowenstein-Jensen medium for the isolation of M. tuberculosis from cerebrospinal fluid samples of tuberculous meningitis patients. Indian J Med Microbiol 25: 236-240, 2007.

15. Delidow B, Lynch JP, Peluso JJ and White BA: Polymerase chain reaction. In: Methods in Molecular Biology, PCR Protocols: Methods and Application. White B (ed). Humana Press Inc. Totowa, NJ, pp1-30, 1998.

16. Kox LF, Rhienthong D, Miranda AM, Udomsantisuk N, Ellis K, van Leeuwen J, van Heusden S, Kuijper S and Kolk AH: A more reliable PCR for detection of Mycobacterium tuberculosis in clinical samples. J Clin Microbiol 32: 672-678, 1994.

17. Ritacco V and de Kantor IN: Simultaneous detection of Mycobacterium bovis and Mycobacterium tuberculosis in human cerebrospinal fluid. J Clin Microbiol 45: 684, 2007.

18. Takahashi $T$ and Nakayama $T$ : Novel technique of quantitative nested real-time PCR assay for Mycobacterium tuberculosis DNA. J Clin Microbiol 44: 1029-1039, 2006.

19. Cole ST, Brosch R, Parkhill J, Garnier T, Churcher C, Harris D, Gordon SV, Eiglmeier K, Gas S, Barry CE III, et al: Deciphering the biology of Mycobacterium tuberculosis from the complete genome sequence. Nature 393: 537-544, 1998.

20. Kato-Maeda M, Rhee JT, Gingeras TR, Salamon H, Drenkow J, Smittipat N and Small PM: Comparing genomes within the species Mycobacterium tuberculosis. Genome Res 11: 547-554, 2001.
21. Tsolaki AG, Hirsh AE, DeRiemer K, Enciso JA, Wong MZ, Hannan M, Goguet de la Salmoniere YO, Aman K, Kato-Maeda M and Small PM: Functional and evolutionary genomics of Mycobacterium tuberculosis: insights from genomic deletions in 100 strains. Proc Natl Acad Sci USA 101: 4865-4870, 2004.

22. Palma-Nicolás JP and Bocanegra-García V: Innovative strategies to diagnose and monitor tuberculosis patients. Arch Bronconeumol 43: 225-232, 2007 (In Spanish).

23. Parrado R, Lozano D, Garcia L, Torrico MC, Delgado R, Torrico F, Laserna M and Reithinger R: Multiprimer PCR system diagnosis of pulmonary tuberculosis in Cochabamba, Bolivia. J Clin Microbiol 46: 830-831, 2008

24. Richardson ET, Samson D and Banaei N: Rapid Identification of Mycobacterium tuberculosis and nontuberculous mycobacteria by multiplex, real-time PCR. J Clin Microbiol 47: 1497-1502, 2009.

25. Siddiqi SH, Hawkins JE and Laszlo A: Interlaboratory drug susceptibility testing of Mycobacterium tuberculosis by a radiometric procedure and two conventional methods. J Clin Microbiol 22: 919-923, 1985.

26. Fuentelsaz Gallego C: Sample size calculation. Matronas Profesion 5: 5-13, 2004. Available: https://ecaths1.s3.amazonaws. com/seminarioi/1400533589.1\%20Muestreo.pdf. (In Spanish)

27. Chomczynski P and Sacchi N: Single-step method of RNA isolation by acid guanidinium thiocyanate-phenol-chloroform extraction. Anal Biochem 162: 156-159, 1987.

28. Chomczynski P: A reagent for the single-step simultaneous isolation of RNA, DNA and proteins from cell and tissue samples. Biotechniques 15: 532-534, 536-537, 1993

29. Dawson B and Trapp RG: Biostatistics, 4 th edition. New York: McGraw Hill, 2004.

30. Del Portillo P, Murillo LA and Patarroyo ME: Amplification of a species-specific DNA fragment of Mycobacterium tuberculosis and its possible use in diagnosis. J Clin Microbiol 29: 2163-2168, 1991.

31. Del Portillo P, Thomas MC, MartínezE, Marañón C, Valladares B, Patarroyo ME and Carlos López M: Multiprimer PCR system for differential identification of mycobacteria in clinical samples. J Clin Microbiol 34: 324-328, 1996.

32. Herrera EA and Segovia M: Evaluation of mtp40 genomic fragment amplification for specific detection of Mycobacterium tuberculosis in clinical specimens. J Clin Microbiol 34: 1108-1113, 1996

33. Nava PO, Manssur H and Prieto L: Evaluation of bacilloscopy, cultivation and polymerase chain reaction for the diagnostic of lung tuberculosis. Kasmera 33: 119-131, 2005 (In Spanish).

34. Ling DI,Flores LL, Riley LW and Pai M: Commercial nucleic-acid amplification tests for diagnosis of pulmonary tuberculosis in respiratory specimens: meta-analysis and meta-regression. PLoS One 3: e1536, 2008.

35. Gori A, Franzetti F, Marchetti G, Catozzi L and Corbellino M: Specific detection of Mycobacterium tuberculosis by mtp40 nested PCR. J Clin Microbiol 34: 2866-2867, 1996.

36. Kolk AH, Schuitema AR, Kuijper S, van Leeuwen J, Hermans PW, van Embden JD and Hartskeerl RA: Detection of Mycobacterium tuberculosis in clinical samples by using polymerase chain reaction and a nonradioactive detection system. J Clin Microbiol 30: 2567-2575, 1992.

37. Lima JF, Montenegro LM, Montenegro RA, Cabral MM, Lima AS, Abath FG and Schindler HC: Performance of nested PCR in the specific detection of Mycobacterium tuberculosis complex in blood samples of pediatric patients. J Bras Pneumol 35: 690-697, 2009.

38. Koivula T, Svenson SB and Källenius G: The mtp40 gene is not present in Mycobacterium bovis. Tuberculosis (Edinb) 82: 183-185, 2002.

39. Vera-Cabrera L, Howard ST, Laszlo A and Johnson WM: Analysis of genetic polymorphism in the phospholipase region of Mycobacterium tuberculosis. J Clin Microbiol 35: 1190-1195, 1997.

40. Seth P, Ahuja GK, Bhanu NV, Behari M, Bhowmik S, Broor S, Dar L and Chakraborty M: Evaluation of polymerase chain reaction for rapid diagnosis of clinically suspected tuberculous meningitis. Tuber Lung Dis 77: 353-357, 1996.

41. Bonington A, Strang JI, Klapper PE, Hood SV, Rubombora W, Penny M, Willers R and Wilkins EG: Use of Roche AMPLICOR Mycobacterium tuberculosis PCR in early diagnosis of tuberculous meningitis. J Clin Microbiol 36: 1251-1254, 1998.

42. Vera-Cabrera L, Hernández-Vera MA, Welsh O, Johnson WM and Castro-Garza J: Phospholipase region of Mycobacterium tuberculosis is a preferential locus for IS6110 transposition. J Clin Microbiol 39: 3499-3504, 2001.

43. Weil A, Plikaytis BB, Butler WR, Woodley CL and Shinnick TM: The mtp40 gene is not present in all strains of Mycobacterium tuberculosis. J Clin Microbiol 34: 2309-2311, 1996. 